\title{
Transhiatal blunt esophagectomy for carcinoma of the esophagus
}

\author{
JOSEPH C. BENEDETTO, DO \\ LARRY W. COHEN, DO \\ MICHAEL I. ABRAHAM, DO
}

Transhiatal blunt esophagectomy has been reported as a safe and effective procedure for the palliation of carcinoma of the esophagus. Avoidance of a thoracotomy eliminates the morbidity associated with this procedure, and creation of a cervical esophagogastric anastomosis avoids the catastrophic sequelae of an intrathoracic anastomotic leak. Moreover, use of the procedure for palliation does not preclude excellent 1-year survival rates.

We report early results in five consecutive patients with esophageal carcinoma who underwent transhiatal blunt esophagectomy. Five patients had 22 complications, including one with a fascial dehiscence, pyloroplasty leak, and localized mediastinal abscess requiring a second laparotomy. One patient died in the hospital postoperatively of massive aspiration pneumonitis.

Our results compare favorably with those reported in the literature. We believe that transhiatal blunt esophagectomy

From the Kennedy Memorial Hospital Medical Center, University of Medicine and Dentistry of New JerseySchool of Osteopathic Medicine, Stratford, NJ. At the time this paper was written, Dr Benedetto was a surgical resident. Dr Cohen is clinical assistant professor of general surgery, and Dr Abraham is clinical associate professor of general surgery.

Reprint requests to Joseph C. Benedetto, DO, 947 Eton Dr, Jacksonville, NC 28546.

avoids the morbidity and mortality of a thoracotomy and an intrathoracic anastomosis, yet remains a major gastrointestinal operative procedure with all of its attendant risks.

Esophageal resection for carcinoma has the highest mortality of any electively performed procedure today. ${ }^{1,2}$ Moreover, survival after resection is poor, with an $18 \%$ survival rate reported after 1 year, $9 \%$ after 2 years, and $4 \%$ after 5 years, based on a review of more than 83,000 patients by Earlam and Cunha-Melo. ${ }^{1}$

Palliation and an attendant need to keep the operative mortality low remain high priorities in esophageal resection for carcinoma. Bypass operations have been unsuccessful, in that mortality after such procedures has been as high as $41.5 \% .^{3}$

The majority of deaths occurring after esophageal resection for carcinoma has resulted from the associated pulmonary complications of a thoracotomy and anastomotic leaks into the chest. ${ }^{3-5}$ In 1978, Orringer and Sloan ${ }^{4}$ described low morbidity and mortality in 26 patients who underwent esophageal resection via a blunt, transhiatal approach without thoracotomy. Since that time, many authors ${ }^{5-13}$ have reported encouraging results from esophagectomy without thoracotomy.

We describe herein our results with blunt transhiatal esophagectomy for malignant disease of the esophagus. 
The \#1 prescribed allergy in the U.S. and worldwide

\section{NO ANTIHISTAMINE}

\section{OLD OR NEW}

IS MORE EFFECTIVE

Maximum efficacy - proven in 30 double-blind clinical studies ${ }^{1-5}$

Fast onset of action - most patients experience significant relief within 1 hour, ${ }^{6+}$ maximum efficacy in 3-4 hours ${ }^{7 * *}$

Efficacy maintained with through-the-season use $8-10$

Unmatched patient preference $-77 \%$ of patients who started on Seldane and obtained another prescription in the category refilled that prescription with Seldane.

(Based upon a 1986 nationwide study of 640 patient members of prepaid group benefit plans.)

$t$ In most hay fever patients $(55 \%)$.

** In studies utilizing the histamine-induced skin wheal test 


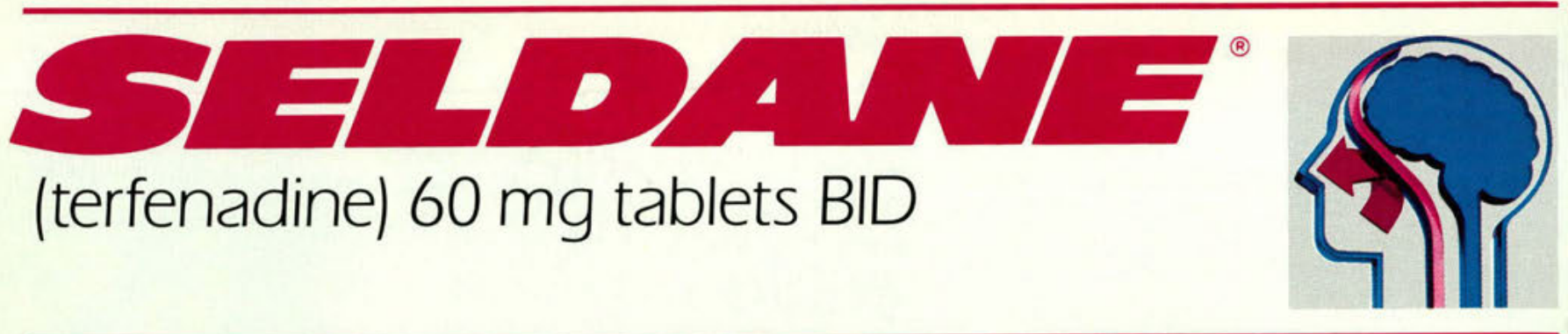

\section{- Fast, unsurpassed relief \\ - Efficacy maintained in through-the-season use B.i.d. dosing for high patient compliance - High patient preference \\ - Lets patients stay alert so they can perform at their best}

\section{Seldane ${ }^{\circledR}$ (terfenadine) $60 \mathrm{mg}$ Tablets \\ BRIEF SUMMARY \\ CAUTION: Federal law prohibits dispensing without prescription. \\ DESCRIPTION}

Seldane (terfenadine) is available as tablets for oral administration. Each tablet contains $60 \mathrm{mg}$ terfenadine. Tablets also contain, as inactive ingredients: corn starch, gelatin, lactose, magnesium stearate, and sodium bicarbonate.

\section{MDICATIONS AND USAGE}

Seldane is indicated for the relief of symptoms associated with seasonal allergic rhinitis such as sneezing, rhinorrhea, pruritus, and lacrimation.

CONTRAINDICATIONS

Seldane is contraindicated in patients with a known hypersensitivity to terfenadine or any of its ingredients.

\section{PRECAUTIONS}

\section{Information for patients}

Patients taking Seldane should receive the following information and instructions. Antihistamines are prescribed to reduce allergic symptoms. Patients should be questioned about pregnancy or lactation before starting Seldane therapy, since the drug should be used in pregnancy or lactation only if the potential benefit justifies the potential risk to fetus or baby. Patients should be instructed to take Seldane only as needed and not to exceed the prescribed dose. Patients should also be instructed to store this medication in a tightly closed container in a cool, dry place, away from heat or direct sunlight, and away from children.

Carcinogenesis, mutagenesis, impairment of fertility

Oral doses of terfenadine, corresponding to 63 times the recommended human daily dose, in mice for 18 months or in rats for 24 months, revealed no evidence of tumorigenicity. Microbial and micronucleus test assays with terfenadine have revealed no evidence of mutagenesis.

Reproduction and fertility studies in rats showed no effects on male or female fertility at oral doses of up to 21 times the human daily dose. At 63 times the human daily dose there was a small but significant reduction in implants and at 125 times the human daily dose reduced implants and increased post-implantation losses were observed, which were judged to be secondary to maternal toxicity.

Pregnancy Category C

There was no evidence of animal teratogenicity. Reproduction studies have been performed in rats at doses 63 times and 125 times the human daily dose and have revealed decreased pup weight gain and survival when terfenadine was administered throughout preonancy and lactation. There are no adequate survival when tertenadine was administered throughout pregnancy and lactation. There are no adequate potential benefit justifies the potential risk to the fetus.

Nonteratogenic effects

Nonteratogenic effects Seldane is not recommended for nursing women. The drug has caused decreased pup weight gain and survival in rats given doses 63 times and 125 times the human daily dose throughout pregnancy and lactation. Effects on pups exposed to Seldane only during lactatio

Pediatric use

Safety and effectiveness of Seldane in children below the age of 12 years have not been established. General

Consideration should be given to potential anticholinergic (drying) effects in patients with lower airway Consideration should be given
disease, including asthma

\section{disease, including asth}

Experience from clinical studies, including both controlled and uncontrolled studies involving more than 2,400 patients who received Seldane, provides information on adverse experience incidence for periods of a few days up to six months. The usual dose in these studies was $60 \mathrm{mg}$ twice daily, but in a small number of patients, the dose was as low as $20 \mathrm{mg}$ twice a day, or as high as $600 \mathrm{mg}$ daily.

In controlled clinical studies using the recommended dose of $60 \mathrm{mg}$ b.i.d., the incidence of reported adverse effects in patients receiving Seldane was similar to that reported in patients receiving placebo. (See Table below.)

ADVERSE EVENTS REPORTED IN CLINICAL TRIALS

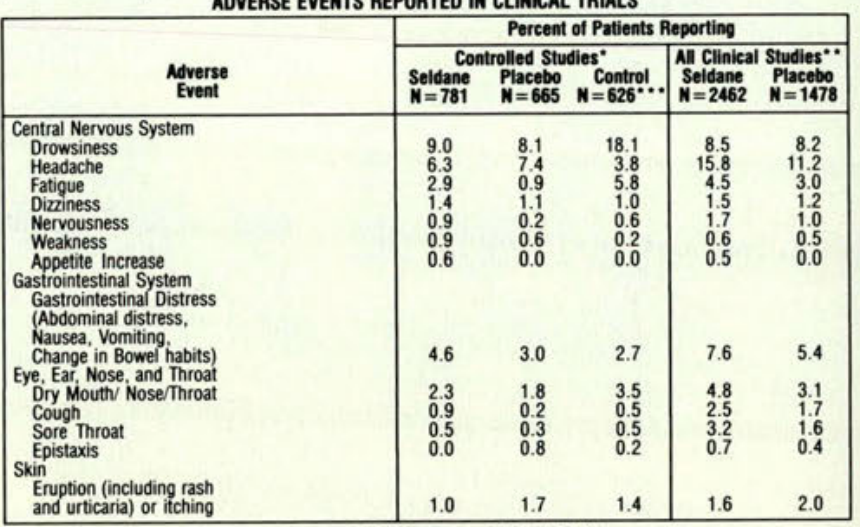

"Duration of treatment in "CONTROLLED STUDIES" was usually 7-14 DAYS

.-Duration of treatment in "ALL CLINICAL STUDIES" was up to 6 months. patients)

In addition to the more frequent side effects reported in clinical trials (See Table), adverse effects have been reported at a lower incidence in clinical trials and/or spontaneously during marketing of Seldane that warrant listing as possibly associated with drug administration. These include: alopecia, (hair loss or thinning), anaphylaxis, angioedema, arrhythmia (including ventricular tachyarrhythmia), bronchosm, confusion, depression galactorrhea hypotension, insomnia, menstrual disorders (including dysmenorrhea), musculoskeletal symptoms, nightmares, palpitation, paresthesia, photosensitivity, prolonged QT interval seizures, sweating, syncope, tachycardia, tremor, urinary frequency, and visual disturbances. In clinical trials, several instances of mild or in one case, moderate transaminase elevations were seen in patients receiving Seldane. Mild elevations were also seen in placebo treated patients. Marketing experiences include isolated reports of jaundice, cholestatic hepatitis, and hepatitis: 列 is a causal relationship of liver abnormalities to Seldane use clear.

\section{OVERDOSAGE}

Information concerning possible overdosage and its treatment appears in Full Prescribing Information. DOSAGE AND ADMINISTRATION

The usual dosage for adults and children 12 years and older is $60 \mathrm{mg}$ ( 1 tablet) twice daily. Product Information as of June, 1988

MERRELL DOW PHARMACEUTICALS INC

Subsidiary of The Dow Chemical Company

Cincinnati, Ohio 45215, U.S.A.

Merrell Dow

PRINTED IN U.S.A.

References: 1. Kemp JP, Buckley CE, Gershwin ME, et al: Multicenter, double-blind, placebo-controlled trial of terfenadine in seasonal allergic rhinitis and Re

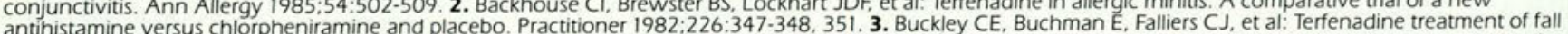

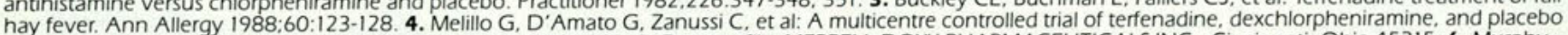
in allergic rhinitis. Arzneim-Forsch/Drug Res 1982:32:1202-1203. 5. Data on file, MERRELL DOW PHARMACEUTICALS INC.. Cincinnati, Ohio 45215. 6. Murphy-

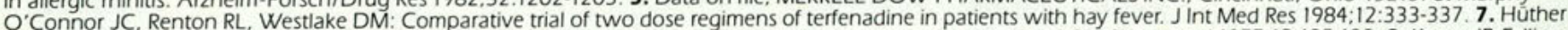

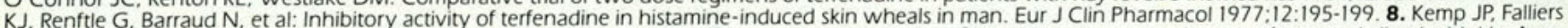

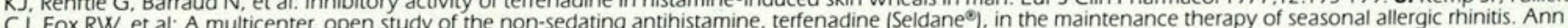
CJ. Fox RW, et al: A multicenter, open study of the non-sedating antihistamine, terfenadine (Seldane 1988 . Simons KJ: Lack of subsensitivity to terfenadine during long-term treatment. J Allergy Clin Immunol 1988:82:1068-1075. 


\section{Patients and methods}

We reviewed the records of five consecutive patients who underwent transhiatal blunt esophagectomy between Jan 1 and Dec 31, 1987. All five had malignant disease of the esophagus; four had squamous cell carcinoma and one had adenocarcinoma arising from Barrett's esophagus. All tumors were located in the distal half of the esophagus; no tumor had invaded the surrounding mediastinal structures; and only one patient had pathologically proved regional lymph node metastases.

All patients had had preoperative chest roentgenograms, computed tomographic scans of the chest and mediastinum, and upper gastrointestinal tract endoscopy with biopsy. In addition, three patients underwent esophageal and upper gastrointestinal tract barium contrast studies, three patients had radionuclide liver-spleen scans, and two patients had radionuclide bone scans. Results of preoperative evaluation for distant metastatic disease was negative in all five patients.

The average age of the patients was 60 years (range, 47 to 74 years). The presenting complaint was dysphagia in four patients and upper abdominal fullness in one patient. Documented weight loss prompted the preoperative administration of total parenteral nutrition in two patients and standard oral liquid nutritional supplements in two patients. One patient received no supplemental nutritional support preoperatively. Postoperatively, three patients with feeding jejunostomy catheters received standard enteral formula feedings. These feedings were begun on the first to third postoperative day and advanced as tolerated. All patients received postoperative parenteral nutritional support until enteral nutrition was adequate.

Significant comorbidities included hypertension in three patients, chronic obstructive pulmonary disease in two patients, and atrial fibrillation, diabetes mellitus, and cerebrovascular accident in one patient each.

Postoperatively, all patients underwent evaluation of their esophagogastric anastomosis for patency and integrity on the fourth to fifth day using water-soluble contrast fluid.
If the study confirmed patency and integrity of the anastomosis, the nasogastric tube was removed and the patient was begun on a clear liquid diet the next day, which was advanced to a regular diet as tolerated.

\section{Operative technique}

The operative technique used in this series is based on that previously described in detail by Orringer and Sloan. ${ }^{4}$ In brief, the abdomen is entered through an upper midline incision and the greater and lesser curvatures of the stomach are mobilized, preserving the right gastric and gastroepiploic vessels. The esophagogastric junction is isolated with a large Penrose drain, and the hiatus is enlarged if necessary to allow the surgeon's hand to enter into the mediastinum. Using finger dissection, the surgeon mobilizes the esophagus from below to as high a point as possible. A pyloroplasty is performed, and the duodenum is mobilized with a Kocher maneuver.

The esophagus is transected at the esophagogastric junction with a stapling device, or division may be continued on to the stomach for esophagogastric junction carcinomas, as described by Orringer and Sloan. ${ }^{4} \mathrm{~A}$ heavy silk suture is then placed through the proximal part of the stomach, and dissection of the neck is performed.

An oblique cervical incision is made along the anterior border of the sternocleidomastoid muscle, and the dissection is carried down anterior to the carotid sheath to the cervical esophagus. Care is taken not to use retractors on the thyroid gland while retracting it medially to prevent injury to the recurrent laryngeal nerve. The esophagus is then encircled with a Penrose drain and bluntly dissected from above, freeing the intrathoracic esophagus. The esophagus is then withdrawn from the cervical incision and divided with a stapling device.

A long, curved uterine packing forceps or red rubber catheter is then passed from above, and the stomach is brought into the posterior mediastinum and out the neck incision using the previously placed silk suture. Care must be taken at this point to assure that the stom- 
ach is not rotated through the mediastinum during mobilization to prevent obstruction. The esophagogastrostomy is then carried out in an end-to-side fashion.

In two patients, a two-layer esophagogastric anastomosis was created with an inner layer of 2-0 absorbable suture and an outer layer of 2-0 silk suture in an interrupted fashion. In another two patients, a single-layer anastomosis was created with use of interrupted 2-0 silk. In one patient, the anastomosis was created with use of an EEA stapler (US Surgical Corp, Norwalk, Conn) via a gastrotomy produced in the anterior wall of the stomach.

After creation of the feeding jejunostomy, the mediastinum and neck are drained separately with the use of closed suction drains, and the operative incisions are closed in a routine fashion. Chest tubes are placed thereafter, if necessary. Nasogastric suction is maintained postoperatively via an intraoperatively placed nasogastric tube until patency and integrity of the anastomosis are confirmed by results of a water-soluble contrast study.

\section{Results}

The average operative time in our series was 5.8 hours (range, 4.75 to 7.75 hours). Average blood loss was $1200 \mathrm{~mL}$ (range, 500 to 2000 $\mathrm{mL}$ ). In all cases, the stomach was mobilized through the mediastinum with sufficient length to perform a tension-free anastomosis. The stomach was used as the esophageal substitute in all patients.

Pneumothorax occurred in three patients intraoperatively; in two cases, it was bilateral. All cases of pneumothorax were easily recognized and treated by tube thoracostomy at the completion of the procedure. In addition, one patient had transient hypotension that was attributed to manual compression of the heart and inferior vena cava during the dissection.

Postoperatively, no anastomotic leaks developed. There were two anastomotic strictures, one of which resolved after a single dilation; the other required multiple dilations. There was one instance of vocal cord paralysis requiring Teflon injection, and one patient had a fascial dehiscence, pyloric leak, and a me- diastinal abscess. This last patient underwent an exploratory laparotomy on the eighth postoperative day, and the fascial dehiscence was repaired. At laparotomy the pyloric perforation and localized abscess were found incidentally. The pyloric leak was closed primarily and reinforced with an omental patch after the abscess was drained. The abdominal wound was closed en masse with use of heavy polypropylene monofilament suture, and the patient was maintained on appropriate antibiotic therapy for 2 weeks postoperatively. The patient was discharged 20 days after the second laparotomy.

Before the second laparotomy, the patient had shown clinical improvement, and results of his postoperative contrast study disclosed no extravasation from either the anastomosis or the pyloroplasty. His complications were attributed to technical failure.

Insignificant atelectasis was seen in three patients. One patient had a left lower lobe and lingular pneumonia, and one patient had massive aspiration pneumonitis, which contributed to her death. In addition, there were two instances of pleural effusion, and one patient had pulmonary edema.

Cardiac complications occurred in three of five patients. These included one episode each of atrial fibrillation, atrial flutter, and bradycardia with hypotension. The last patient had atrial fibrillation preoperatively and showed bradycardia with hypotension in association with an episode of massive aspiration.

Additional complications included wound infection in one patient and paralytic ileus in one patient.

No deaths occurred within 30 days of operation. However, in one patient, massive aspiration developed on the tenth postoperative day, which resulted in a prolonged and complicated hospital course that ended in her death on the 108th postoperative day.

\section{Survival}

Of the four surviving patients, one was lost to follow-up after 10 months. One patient died of cardiac causes 15 months postoperatively. At the time of his death, no evidence of recur- 
rence or metastasis was noted. Two patients have had no evidence of recurrence or metastasis after 13 months and 18 months, respectively.

\section{Discussion}

Blunt transhiatal esophagectomy has been enthusiastically supported by Orringer and Sloan $^{4}$ and Orringer and Orringer ${ }^{5}$ as the procedure of choice for malignant disease of the esophagus. In a study of 134 consecutive patients undergoing transhiatal esophagectomy for both benign and malignant disease, Orringer and Orringer ${ }^{5}$ reported an $8 \%$ operative mortality. Results of subsequent investigators have supported blunt transhiatal esophagectomy as a relatively safe procedure with an acceptable morbidity and mortality when compared with esophagectomy using a standard thoracoabdominal approach. , $^{2,13}$

The reason for the decreased mortality associated with transhiatal esophagectomy is the avoidance of a thoracotomy and its pulmonary complications, as well as the avoidance of an intrathoracic anastomosis and its risk of leakage. ${ }^{4}$ Postlethwait ${ }^{3}$ reviewed more than 500 operations for squamous cell carcinoma of the esophagus. He found that the most frequent causes of death in that series were anastomotic leak and pulmonary complications.

The small number of patients in the present study precludes any meaningful statistical analysis; however, our results compare favorably with those reported in the literature.

The average intraoperative blood loss of $1200 \mathrm{~mL}$ in our patients is not significantly different from the $1150 \mathrm{~mL}$ that Orringer and Orringer reported in their series. ${ }^{5}$

Our mean operative time of 5.8 hours is longer than the 2 to 4 hours cited in the literature. 6,9 This factor is expected to improve as we gain more experience with the technique.

The $60 \%$ rate of pneumothorax is slightly higher than the $51 \%$ incidence reported by Orringer and Orringer ${ }^{5}$; however, this complication was easily recognized and treated without long-term sequelae. As we gain more experience with the technique of blunt esophagec- tomy, the incidence of pneumothorax should decrease.

None of our five patients had an anastomotic leak, which is well within the reported range $(0 \%$ to $19 \%)$ for transhiatal blunt esophagectomy. ${ }^{2,5-11,13}$ Moreover, when anastomotic leaks do occur, they are usually easily managed without a repeated operation because of their location in the neck. . $^{2,8-10,13}$

Pulmonary complications were relatively common in our series; however, most were minor and easily treated. Only one serious pulmonary complication occurred in our series. This was a massive aspiration pneumonitis that contributed to the subsequent death of the patient.

Permanent vocal cord paralysis occurred in one patient for an incidence of $20 \%$. Reports in the literature cite a $4 \%$ to $37 \%$ incidence of vocal cord injuries of variable severity, ranging from transient hoarseness to permanent vocal cord paralysis that requires Teflon injection. ${ }^{2,5,7-10,12}$ Following the recommendations of Stewart and colleagues, ${ }^{8}$ we have avoided using metal retractors in the patient's neck during our later cases to avoid injury to the recurrent laryngeal nerve.

One patient died in the hospital, for a mortality rate of $20 \%$. Although the patient's death was not a direct consequence of the operation, some abnormality of gastric motility contributed to the development of aspiration pneumonitis. Postoperative upper gastrointestinal evaluation of this patient revealed no obstruction to emptying, although passage of contrast through the stomach was delayed. Similar delays in gastric emptying have been described, usually as a transient and inconsequential problem. ${ }^{11}$

On discharge from the hospital, all four patients were able to eat regular diets; only two patients required bougienage, and one patient needed multiple dilations.

Our 1-year survival rate of $60 \%$ is excellent when compared with the $18 \%$ 1-year survival rate reported by Earlam and Cunha-Melo ${ }^{1}$ and the $35 \%$ 1-year survival rate reported by Orringer and Orringer. ${ }^{5}$ Baker and Schecter, ${ }^{10}$ however, described survival rates at 1 year of $86 \%$ 
for those with upper esophageal cancer and $88 \%$ for those with lower esophageal cancer in their series. It is too early to comment on our 2- and 5-year results.

Despite the high morbidity rate in our series of 22 complications in five patients, we believe that our early results compare favorably with those reported in the literature. Our patients had only two major complications: one pyloroplasty leak with abscess and one massive aspiration pneumonitis. The remainder represented a large number of relatively inconsequential complications that are intrinsic to this procedure or that might be expected after any major gastrointestinal operation.

\section{Summary}

We believe that transhiatal blunt esophagectomy is a relatively safe and effective procedure for palliation of carcinoma of the esophagus. Avoidance of a thoracotomy eliminates the morbidity associated with this procedure, and creation of a cervical esophagogastric anastomosis avoids the catastrophic sequelae of an intrathoracic anastomotic leak. Moreover, use of the procedure for palliation does not preclude an excellent 1-year survival rate.

1. Earlam R, Cunha-Melo JR: Oesophageal squamous cell carcinoma: I. A critical review of surgery. Br J Surg 1980;67:381390.

2. Steiger Z, Wilson RF: Comparison of the results of esophagectomy with and without a thoracotomy. Surg Gynecol Obstet 1981;153:653-656.

3. Postlethwait RW: Complications and deaths after operations for esophageal carcinoma. $J$ Thorac Cardiovasc Surg 1983;85:827-831.

4. Orringer MB, Sloan H: Esophagectomy without thoracotomy. $J$ Thorac Cardiovasc Surg 1978;76:643-654.

5. Orringer MB, Orringer JS: Esophagectomy without thoracotomy: A dangerous operation? J Thorac Cardiovasc Surg 1983;85:72-80.

6. Szentpetery S,. Wolfgang T, Lower RR: Pull-through esophagectomy without thoracotomy for esophageal carcinoma. Ann Thorac Surg 1979;27:399-403.

7. Yonezawa T, Tsuchiya S, Ogoshi S, et al: Resection of cancer of the thoracic esophagus without thoracotomy. $J$ Thorac Cardiovasc Surg 1984;88:146-149.

8. Stewart JR, Sarr MG, Sharp KW, et al: Transhiatal (blunt) esophagectomy for malignant and benign esophageal disease: Clinical experience and technique. Ann Thorac Surg 1985;40:343-348.
9. Kron IL, Joob AW, Levine PA, et al: Blunt esophagectomy and gastric interposition for tumors of the cervical esophagus and hypopharynx. Am Surgeon 1986;52(3):140-141.

10. Baker JW, Schechter GL: Management of panesophageal cancer by blunt resection without thoracotomy and reconstruction with stomach. Ann Surg 1986;203:491-499.

11. Ujiki GT, Pearl GJ, Poticha S, et al: Mortality and morbidity of gastric 'pull-up' for replacement of the pharyngoesophagus. Arch Surg 1987;122:644-647.

12. Hwang TL, Shen-Chen SM, Chen MF: Nonthoracotomy esophagectomy for corrosive esophagitis with gastric perforation. Surg Gynecol Obstet 1987;164:537-540.

13. Spitz L, Kiely E, Sparnon T: Gastric transposition for esophageal replacement in children. Ann Surg 1987;206(1):69-73. 